\title{
Local infiltration analgesia in primary total knee arthroplasty
}

\author{
YY Fang *, QJ Lee, Esther WY Chang, YC Wong
}

\section{A B S T R A C T}

Introduction: Postoperative pain in total knee arthroplasty (TKA) can hinder rehabilitation and cause morbidity. Local infiltration analgesia (LIA), comprising an anaesthetic drug, non-steroidal anti-inflammatory drug, and adrenaline, has been introduced to reduce pain and systemic side-effects. This study evaluated the efficacy of LIA in TKA with respect to morphine consumption and postoperative pain score.

Methods: This single-centre retrospective cohort study recruited patients with knee osteoarthritis who were scheduled for primary TKA during the period from January 2017 to December 2017. Patients with chronic inflammatory joint disease, contra-indications for LIA, or dementia were excluded. Patients in the LIA group were administered single-dose LIA intra-operatively, while those in the control group were not. Primary outcomes were postoperative pain score, morphine demand, and morphine consumption; secondary outcomes were range of motion, quadriceps power, and postoperative length of stay.

This article was published on 5 Aug 2019 at www.hkmj.org.
Results: In total, 136 patients were recruited (68 per group). Total postoperative morphine demand and consumption, as well as pain scores from postoperative day (POD) 1 to POD 4, were lower in the LIA group than in the control group. The range of motion from POD 1 to POD 4 and quadriceps power on POD 1 were higher in the LIA group than in the control group. Quadriceps power from POD 2 to POD 4 and postoperative length of stay were not significantly different between groups.

Conclusions: Intra-operative single-dose LIA can effectively reduce postoperative pain, morphine demand, and morphine consumption. Therefore, the use of LIA is recommended during TKA.

\section{${ }^{1}$ YY Fang *, MB, BS \\ ${ }^{2}$ QJ Lee, FCSHK, FHKCOS \\ ${ }^{2}$ EWY Chang, MSc \\ ${ }^{2}$ YC Wong, FHKCOS}

Hong Kong Med J 2019;25:279-86

https://doi.org/10.12809/hkmj187756

Department of Orthopaedics and Traumatology, Princess Margaret Hospital, Laichikok, Hong Kong

${ }^{2}$ Department of Orthopaedics and Traumatology, Yan Chai Hospital, Tsuen Wan, Hong Kong

* Corresponding author: yingyan.f.mbbs@gmail.com

New knowledge added by this study

- After total knee arthroplasty (TKA), postoperative morphine demand and consumption, as well as pain scores from postoperative day (POD) 1 to POD 4, were lower in the local infiltration analgesia (LIA) group than in the control group.

- The range of motion from POD 1 to POD 4 and quadriceps power on POD 1 were greater in the LIA group than in the control group.

- Quadriceps power from POD 2 to POD 4 and postoperative length of stay were not significantly different between groups.

Implications for clinical practice or policy

- Intra-operative administration of LIA effectively reduced postoperative patient pain and consumption of morphine.

- Routine use of LIA in TKA protocols may facilitate more rapid recovery from surgery through earlier return of range of motion and quadriceps power.

\section{Introduction}

Total knee arthroplasty (TKA) is a common orthopaedic procedure to relieve the problem of end-stage degenerative knee osteoarthritis, particularly in the context of the ageing population, increasing incidence of degenerative joint diseases, and modern emphasis on quality of life. However, TKA is associated with significant postoperative pain, which can hinder rehabilitation and cause morbidity. ${ }^{1}$ Various methods for pain relief have been introduced, including epidural analgesia, peripheral nerve blocks, local infiltration analgesia (LIA), intravenous patient-controlled analgesia, and oral analgesia. Spinal anaesthesia has been associated with severe complications, such as postoperative headache, intra-operative hypotension, and risk of spinal infection. ${ }^{1}$ In addition, intravenous or oral narcotics can cause nausea, vomiting, somnolence, 


\section{局部麻醉於全膝關節置換術中應用的效果}

\section{范盈欣、李君哲、曾慧儀、黃耀忠}

引言：全膝關節置換術（TKA）的術後疼痛會有礙術後康復及增加併 發症發病率。因此, 由麻醉藥、非類固醇止痛藥和腎上腺素混合而成 的局部麻醉混合針（LIA）愈趨盛行, 以減輕術後疼痛和系統性併發 症。本研究旨在以TKA術後疼痛和嗎啡用量探討LIA的成效。

方法：本隊列研究對象為本地一間醫院內, 於2017年1月至12月進行 初次TKA的退化性關節炎患者。研究納入條件為退化性膝關節患者; 排除條件為類風濕性關節炎、對LIA有敏感或不良反應以及腦退化患 者。實驗組患者會在手術中接受LIA，對照組則沒有任何術中止痛藥 注射。研究的主要指標為患者的主觀痛楚、自控嗎啡需求和用量 ; 次 要指標為膝關節的術後屈曲幅度、四頭肌力量和術後住院時間。

結果：實驗組及對照組各有 68 例。實驗組患者在術後第 1 至 4 天有較輕 微的術後痛楚、較低嗎啡需求和用量以及較佳膝關節屈曲幅度。在術 後第 1 天, 實驗組患者的四頭肌力量比控制組患者為大。在術後第 2 至 4 天, 兩組患者的四頭肌力量和術後留院時間沒有顯著分別。

結論：建議術中使用LIA, 能有效減輕術後疼痛、減少嗎啡需求和用 量。

\section{Patients and study population}

This study was approved by the Kowloon West Cluster Research Ethics Committee. The study cohort consisted of Chinese patients aged $\geq 18$ years with knee osteoarthritis who were scheduled to undergo primary TKA during the period from January 2017 to December 2017 in Yan Chai Hospital in Hong Kong. Exclusion criteria were the presence of chronic inflammatory joint disease (eg, rheumatoid arthritis or Charcot arthropathy); current use of other medications or measures that may alter pain tolerance (eg, regular steroid or opioid use, nerve blocks, or epidural anaesthesia); presence of dementia; presence of conditions precluding the use of LIA (eg, allergy or intolerance to a drug used in LIA, renal insufficiency, bleeding disorder, or prolonged QT interval). The use of LIA in TKA began on 14 June 2017. Therefore, there were two matched cohorts in this study: the control group was recruited before 14 June 2017, when LIA was not yet used; the LIA group was recruited on or after 14 June 2017, when LIA was routinely administered if not contra-indicated.

respiratory depression, and urinary retention. ${ }^{1}$ Thus, LIA has become increasingly popular for its potential to avoid these complications.

Local infiltration analgesia was first described by Kerr and Kohan ${ }^{2}$ in Australia in 2008. It involves use of a mixture of an anaesthetic drug and a non-steroidal anti-inflammatory drug, to which adrenaline or a corticosteroid can be added. ${ }^{3}$ Local infiltration analgesia is administered intraoperatively through injection into the posterior capsule of the knee, as well as the soft tissues around the surgical field. ${ }^{3,4}$ There is increasing evidence to support the use of LIA in TKA. ${ }^{4-8}$ However, other studies have shown that the efficacy of LIA during TKA is not superior to that of previously available methods. ${ }^{9-11}$ In addition, the use of LIA is reportedly safe, ${ }^{1,12-15}$ but has only recently been adopted in medical centres in Hong Kong. To the best of our knowledge, there have been no studies of the efficacy of LIA in patients undergoing TKA in Hong Kong.

We aimed to investigate the efficacy of LIA in patients with knee osteoarthritis undergoing TKA. The primary outcomes of this study were pain scores and morphine consumption from postoperative day (POD) 1 to POD 4. The secondary outcomes of this study were range of motion, quadriceps power, and postoperative length of stay.

\section{Methods}

\section{Study design}

This was a single-centre, retrospective cohort study based in Yan Chai Hospital, a joint centre in Hong Kong.

\section{Study procedures} in this study, including preoperative blood tests and relevant X-rays. Written informed consent for TKA was provided by each patient. As noted above, the use of LIA in the centre began on 14 June 2017; therefore, patients who underwent TKA on or after that date also gave written informed consent to receive LIA, provided that they did not have any contra-indications to LIA. Antibiotic prophylaxis was administered to each patient prior to operation. surgeons in Yan Chai Hospital, using the medial parapatellar approach. A tourniquet was applied to the operated limb with pressure 2 times the systolic blood pressure; the tourniquet was released after wound closure. Cemented prostheses were used in all cases.

Intra-operative single-dose LIA was administered to patients in the LIA group. The LIA mixture consisted of $30 \mathrm{mg}$ ketorolac, 100 $\mathrm{mg}$ levobupivacaine, and $0.5 \mathrm{mg}$ adrenaline; these components were diluted in normal saline to a final volume of $100 \mathrm{~mL}$, using sterile technique. The LIA mixture was prepared in two $50-\mathrm{mL}$ syringes with 19-gauge needles for injection, and injection was performed at three time points. The first injection was performed before prosthesis cementation and implantation. The posterior capsule was infiltrated with approximately $20 \%$ of the total volume of LIA. During infiltration, the midpoint of the posterior capsule was avoided, due to the close proximity of
Baseline assessments were performed for all patients

All TKA procedures were performed by 
the neurovascular bundle. The second injection was performed after prosthesis implantation: 60\% of the total volume of LIA was infiltrated into the released collateral ligaments, both gutters, anterior supracondylar soft tissue, quadriceps cut ends, and retinaculum. The third injection was performed immediately before skin closure: the remaining $20 \%$ of the total LIA volume was injected subcutaneously. For the control group, no LIA was administered. A suction drain at $200 \mathrm{~mm} \mathrm{Hg}$ was inserted in all patients, and was removed on POD 1.

In both control and LIA groups, the same postoperative protocol was followed. Immediately postoperatively, each patient received instruction from a nurse regarding the use of patient-controlled anaesthesia (PCA), which comprised $1 \mathrm{mg} / \mathrm{mL}$ morphine. When patients experienced pain, they could self-administer $1 \mathrm{mg}$ of morphine intravenously. To prevent overdose, the lockout interval was set at 6 minutes, and the 4-hour maximum morphine dose was $30 \mathrm{mg}$. Patient-controlled anaesthesia was discontinued on POD 1 or 2 , in accordance with the anaesthetist's assessment. In addition to intravenous morphine, oral analgesics were administered; these included $1 \mathrm{~g}$ acetaminophen 4 times daily for 6 days and $50 \mathrm{mg}$ tramadol 4 times daily for 4 days. After the administration period of oral analgesics ( 6 days for acetaminophen and 4 days of tramadol), these oral analgesics were administered only when necessary. Physiotherapy to achieve full weight-bearing walking was offered to all patients on POD 1. Routine deep vein thrombosis screening was performed once, on or after POD 3 by Doppler ultrasound in the Radiology Department of Yan Chai Hospital.

\section{Outcomes}

Primary outcomes were visual analogue scale (VAS) pain score during the period from POD 1 to POD 4 and total morphine use. Visual analogue scale pain scores were rated by patients using a scale of 0 to 10 , where 0 was no pain and 10 was the highest pain imaginable. The amounts (in milligrams) of morphine demanded and consumed by each patient were recorded; there may be a discrepancy between these two values because a lockout interval and maximum dose of morphine were set in the PCA machine to avoid patient overdose. As noted above, PCA was discontinued on either POD 1 or POD 2, in accordance with the anaesthetist's assessment.

Secondary outcomes were range of motion (ie, degrees of active flexion) during the period from POD 1 to POD 4, quadriceps power during the period from POD 1 to POD 4, and postoperative length of stay. Degrees of active flexion and quadriceps power were used because both have been shown to positively influence rehabilitation and functional ability ${ }^{16,17}$ Degrees of active flexion was measured by the attending physician during daily ward rounds, using a goniometer; measurements were corrected to the nearest 5 degrees. Quadriceps power was also rated by the attending physician during daily ward rounds, using the Medical Research Council rating scale of 0 to $5 .{ }^{18}$ Quadriceps power $\geq 3$ was used as a cut-off in the present study; the percentage of patients in each group with quadriceps power $\geq 3$ was assessed during the period from POD 1 to POD 4. Postoperative length of stay was recorded as the number of days that patients remained in the hospital after TKA.

\section{Sample size}

The primary outcomes were postoperative VAS pain score and total morphine consumption. Previous studies assessed VAS pain score using scales of 0 to 10 (where $0=$ no pain and $10=$ extreme pain) or 0 to $100 \mathrm{~mm}$ (where $0=$ no pain and $100=$ extreme pain) with 10 -mm increments. ${ }^{19-25}$ In previous studies that have used a 10-point VAS pain score scale, mean (standard deviation) postoperative VAS pain score was 6.1 (1.1) in the control group. 2,19,20,26 Therefore, a reduction of 1 point in the VAS pain score was considered to be a clinically relevant difference. The sample size for the present study was calculated using an alpha level of 0.05 and $80 \%$ power. With these assumptions, a sample size of 19 patients per group was needed to detect a 1-point reduction in VAS pain score (ClinCalc.com; clincalc.com/stats/ samplesize.aspx). In addition, a reduction of $40 \%$ in morphine usage was considered to be a clinically relevant difference. ${ }^{27}$ Based on previous studies, the mean (standard deviation) of total morphine usage was 20.6 (6.8) mg. ${ }^{2,28}$ Using the above alpha and power values, a sample size of 11 patients per group was needed to detect a $40 \%$ reduction in morphine usage.

To allow for analysis of secondary outcomes and attrition due to missing data, a more conservative sample size estimation was adopted. The estimated sample size for range of motion was 57 patients per group, based on the report published by Zhang et $\mathrm{al}^{29}$ and a $5 \%$ increase in degree of flexion being considered clinically relevant. To allow $15 \%$ attrition due to missing data, a sample size of 68 patients per group was used.

\section{Statistical analysis}

Statistical analyses were performed with SPSS (Windows version 23.0; IBM Corp, Armonk [NY], United States). The Chi squared test was used to analyse categorical variables between two groups (LIA and control). The Shapiro-Wilk test was used to determine whether data followed a normal distribution. The independent samples $t$ test and Mann-Whitney $U$ test were used to compare respective parametric and non-parametric 
continuous data between the two groups. Differences with $\mathrm{P}<0.05$ were considered to be statistically significant.

TABLE I. Patient demographic data*

\begin{tabular}{lccc}
\hline & LIA $(\mathbf{n = 6 8 )}$ & Control $(\mathbf{n = 6 8 )}$ & P value \\
\hline Age (years) & $71.7 \pm 6.5$ & $70.9 \pm 7.2$ & 0.502 \\
Sex & & & 0.583 \\
Women & $64.7 \%$ & $70.6 \%$ & \\
Men & $35.3 \%$ & $29.4 \%$ & \\
BMI (kg/m $\left.{ }^{2}\right)$ & $26.76 \pm 4.08$ & $28.10 \pm 5.83$ & 0.122 \\
ASA & & & 0.449 \\
Class I & $5(7.4 \%)$ & $6(8.8 \%)$ & \\
Class II & $47(69.1 \%)$ & $40(58.8 \%)$ & \\
Class III & $16(23.5 \%)$ & $22(32.4 \%)$ & \\
SA:GA ratio & 2.24 & 2.78 & 0.569 \\
\hline
\end{tabular}

Abbreviations: ASA = American Society of Anesthesiologists status; $\mathrm{BMI}=$ body mass index; GA = general anaesthesia; LIA = local infiltration analgesia; SA = spinal anaesthesia

* Data are shown as mean \pm standard deviation or No. (\%) of patients, unless otherwise specified

\section{Results}

A total of 136 knees were recruited (68 per group). There were no significant differences between the groups with respect to baseline demographic data (Table 1). The results of the Shapiro-Wilk test showed that the following data were not normally distributed: VAS pain score, morphine consumption, degrees of active flexion, and postoperative length of stay.

\section{Complications}

There were no cases of wound infection, delayed wound healing, or prolonged wound drainage. One patient in the LIA group experienced medial tibial plateau fracture intra-operatively; the fracture was repaired using a screw. One patient in the LIA group had an incidental finding of popliteal vein aneurysm during routine postoperative Doppler ultrasound screening for deep vein thrombosis.

\section{Primary outcomes}

\section{Visual analogue scale pain score}

As noted above, VAS pain score data followed a non-normal distribution. Thus, the Mann-Whitney $U$ test was used for comparison between the two

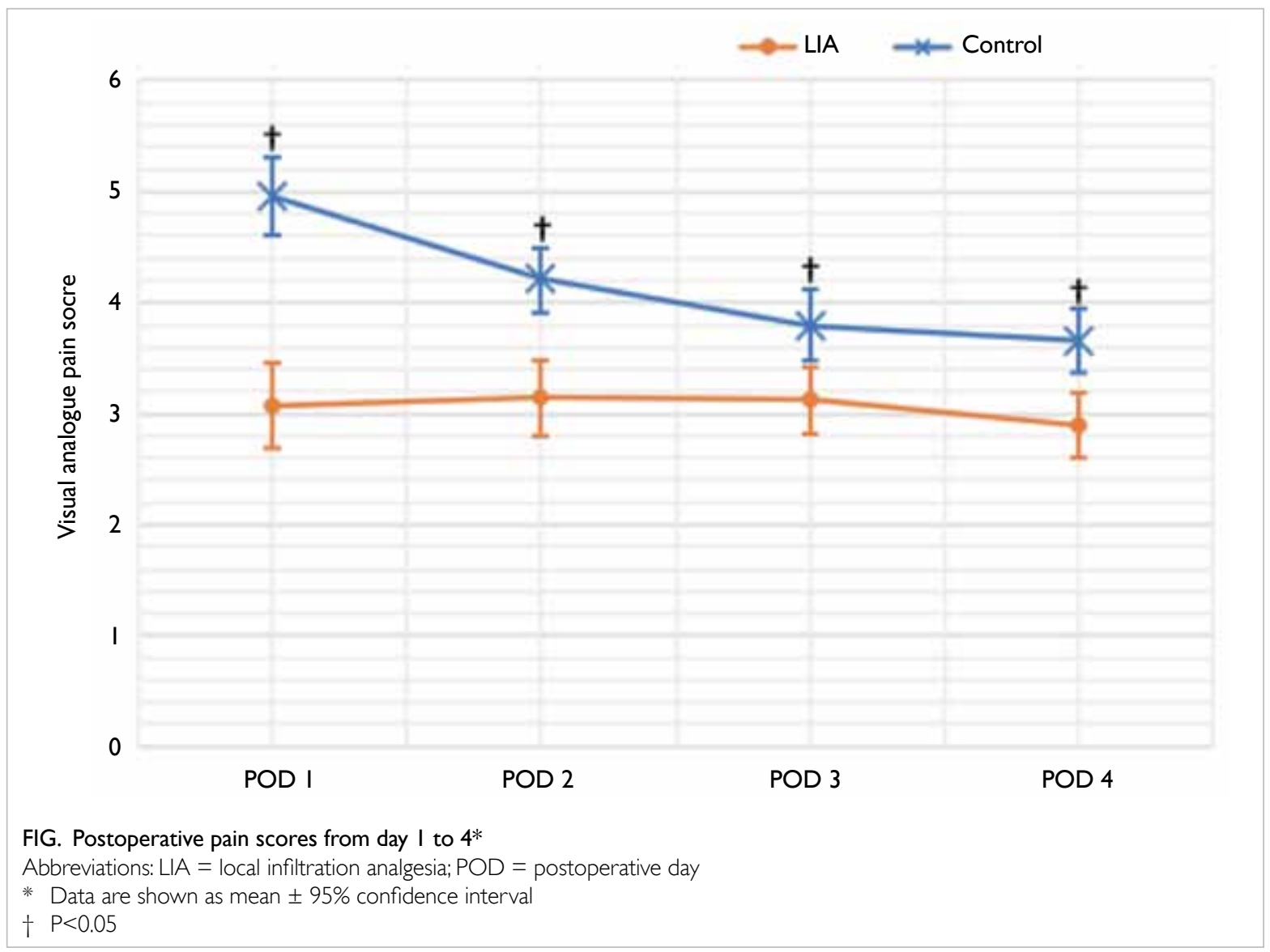


TABLE 2. Degrees of active flexion from postoperative day I to 4

\begin{tabular}{llll}
\hline & LIA group & Control & P value \\
\hline POD 1 & $36.25^{\circ}\left(95 \% \mathrm{Cl}=32.02^{\circ}-40.48^{\circ}\right)$ & $30.07^{\circ}\left(95 \% \mathrm{Cl}=27.40^{\circ}-32.75^{\circ}\right)$ & 0.049 \\
POD 2 & $49.34^{\circ}\left(95 \% \mathrm{Cl}=44.36^{\circ}-54.31^{\circ}\right)$ & $41.84^{\circ}\left(95 \% \mathrm{Cl}=38.36^{\circ}-45.31^{\circ}\right)$ & 0.023 \\
POD 3 & $62.28^{\circ}\left(95 \% \mathrm{Cl}=56.99^{\circ}-67.57^{\circ}\right)$ & $53.91^{\circ}\left(95 \% \mathrm{Cl}=48.38^{\circ}-59.45^{\circ}\right)$ & 0.04 \\
POD 4 & $72.35^{\circ}\left(95 \% \mathrm{Cl}=66.98^{\circ}-77.73^{\circ}\right)$ & $62.50^{\circ}\left(95 \% \mathrm{Cl}=54.48^{\circ}-70.52^{\circ}\right)$ & 0.02 \\
\hline
\end{tabular}

Abbreviations: $95 \% \mathrm{Cl}=95 \%$ confidence interval; $\mathrm{POD}=$ postoperative day

TABLE 3. Percentages of patients with quadriceps power $\geq 3$

\begin{tabular}{lccc}
\hline & LIA group & Control & P value \\
\hline POD 1 & $70.6 \%$ & $29.4 \%$ & $<0.001$ \\
POD 2 & $82.4 \%$ & $69.1 \%$ & 0.072 \\
POD 3 & $85.3 \%$ & $77.9 \%$ & 0.268 \\
\hline POD 4 & $88.2 \%$ & $86.4 \%$ & 0.745 \\
\hline
\end{tabular}

Abbreviation: POD = postoperative day

groups. Patients in the LIA group had significantly lower pain scores during the period from POD 1 to POD 4, compared with patients in the control group (Fig). On POD 1, the mean VAS pain score was 3.07 in the LIA group, compared with 4.96 in the control group $(\mathrm{P}<0.001)$; on POD 2, the LIA group had a pain score of 3.14, compared with 4.21 in the control group $(\mathrm{P}<0.001)$. Differences in pain score on POD 3 and POD 4 were smaller, but remained statistically significant. On POD 3, the pain score in the LIA group was 3.12, while that in the control group was $3.79(\mathrm{P}=0.001)$; on POD 4, the pain score in the LIA group was 2.89, while that in the control group was $3.66(\mathrm{P}<0.001)$ [Fig].

\section{Morphine consumption}

The mean amount of morphine demanded by patients through PCA in the LIA group was 20.10 $\mathrm{mg}$, whereas that in the control group was $29.85 \mathrm{mg}$ $(\mathrm{P}<0.001$, Mann-Whitney $U$ test). The mean amount of morphine consumed by patients in the LIA group was $11.85 \mathrm{mg}$, while that in the control group was $19.54 \mathrm{mg}(\mathrm{P}<0.001$, Mann-Whitney $U$ test $)$.

\section{Secondary outcomes}

\section{Range of motion}

The range of motion (degrees of active flexion) in the LIA group was significantly greater than that in the control group during the period from POD 1 to POD 4 ( $\mathrm{P}<0.05$ for all comparisons, Mann-Whitney $U$ test) [Table 2].

\section{Quadriceps power}

The percentage of patients with quadriceps power $\geq 3$ was compared between the two groups using the Chi squared test. On POD 1, 70.6\% of patients in the LIA group had quadriceps power $\geq 3$, compared with $29.4 \%$ of patients in the control group $(\mathrm{P}<0.001)$. On POD 2, POD 3, and POD 4, there was a trend suggestive of a higher percentage of patients in the LIA group with quadriceps power $\geq 3$, but the difference was not statistically significant (Table 3 ).

\section{Postoperative length of stay}

The postoperative length of stay did not significantly differ between LIA and control groups (5.49 days vs 6.29 days; $\mathrm{P}=0.092$, Mann-Whitney $U$ test).

\section{Discussion}

Pain is an important concern during and immediately after TKA, as it affects patients' quality of life and can hinder rehabilitation progress. A single intraoperative dose of LIA consisting of a mixture of levobupivacaine, ketorolac, and adrenaline improved postoperative pain control, as evidenced by reduced VAS pain scores during the period from POD 1 to POD 4 in the present study. Some previous studies ${ }^{2,29}$ demonstrated no significant differences in pain score between LIA and control groups from POD 1 onwards. In more recent studies by Vaishya et $\mathrm{al}^{8}$ and Fan, ${ }^{30}$ pain-relieving effects of LIA were observed through POD 3, which was similar to the findings of significantly lower pain scores through POD 4 in our study. In addition, differences in pain scores between groups appeared to be greater on POD 1 and POD 2 than on POD 3 and POD 4.

There is no gold standard for LIA. Briefly, it consists of a local anaesthetic, non-steroidal anti-inflammatory drug, and adrenaline; some authors have added morphine and/or steroid to the mixture. ${ }^{24,30-32}$ Most studies have used ropivacaine as the local anaesthetic, while some used bupivacaine. The only previous study performed in Hong Kong ${ }^{30}$ and the present study both used levobupivacaine. According to Casati and Putzu, ${ }^{15}$ ropivacaine and levobupivacaine were developed to avoid bupivacaine-related severe toxicity. Compared with bupivacaine, ropivacaine and levobupivacaine have slightly lower anaesthetic potency; however, 
they exhibit lower central nervous system and cardiovascular toxicity. There is an increasing trend for using ropivacaine or levobupivacaine in LIA, rather than bupivacaine. ${ }^{15}$ Because of the variations in LIA mixtures, it is difficult to identify the 'most effective' component or components. Thus, further studies are needed to support standardisation of LIA.

Both morphine demand and consumption were lower in the LIA group. Because PCA in this study included the use of a lockout interval to avoid morphine overdose, we analysed morphine demand, which more accurately reflected the need for pain control in each patient. Previous studies have reported convincing evidence for lower morphine consumption in patients who had received LIA during TKA. 1,2,21-23,27,28,30,31,33 However, none of the previous studies assessed morphine demand. In the present study, the reduction of both morphine demand and consumption in the LIA group further support the conclusion that the use of LIA improved pain control after TKA.

An incidental finding of popliteal vein aneurysm was noted in one patient in the LIA group. Venous aneurysm is rare, but can be a source of thromboembolism. ${ }^{34}$ Nearly all patients described in the literature were symptomatic, and the most common symptoms were pulmonary embolism and post-thrombotic syndrome..$^{35}$ The definition of venous aneurysm remains controversial. According to Sadowska et $\mathrm{al}^{36}$ the diameter of a normal popliteal vein varies from 5 to $12 \mathrm{~mm}$ in women and 7 to $13 \mathrm{~mm}$ in men; some authors have suggested that the diameter of the venous aneurysm should be twice the normal diameter, while other reports have suggested that it should be at least 3 times the normal diameter. ${ }^{35}$ In the present study, the patient had a fusiform dilatation (anteroposterior diameter $=22$ $\mathrm{mm}$; length $=20 \mathrm{~mm}$ ) of the popliteal vein with reflux noted. The popliteal vein aneurysm was in the distal portion of the popliteal fossa, immediately proximal to the branching of the saphenous vein, which was not involved; the popliteal vein was posterior and lateral to the popliteal artery at that level, and there was no intraluminal thrombus. The patient remained asymptomatic throughout and was referred to vascular specialists in our hospital for further follow-up; repeated duplex ultrasound by the vascular specialists at 4 months postoperatively showed no progression of the aneurysm. The popliteal vein was fully compressible without any thrombus. In addition, there was no aneurysm or pseudoaneurysm in the popliteal artery; thus, the patient continues to receive conservative treatment.

The pathogenesis of popliteal vein aneurysm is uncertain. Possible causes include congenital weakness, trauma, inflammation, and localised degenerative changes. ${ }^{35}$ A popliteal vein aneurysm has been reported as a result of post-arthroscopy trauma, ${ }^{37}$ but has not been associated with TKA. Nonetheless, popliteal artery pseudoaneurysm is an uncommon complication of TKA that has been previously reported. ${ }^{38,39}$ Pseudoaneurysm implies that trauma to the artery may have occurred during TKA, which may comprise direct incision, injury during the injection of LIA, or blunt instrument trauma (eg, from an oscillating saw). With the increasing use of LIA, it is important to consider the risk of vascular complications during injection into the posterior capsule. The potential for popliteal pseudoaneurysm after LIA is not yet known. We consider it to be unlikely that the popliteal aneurysm in our patient was a complication of TKA and/or LIA.

\section{Conclusion}

Intra-operative single-dose LIA can effectively reduce postoperative pain during the period from POD 1 to POD 4, and can reduce both the demand and consumption of morphine. Therefore, we recommend the use of LIA in TKA. Further studies are warranted to evaluate the impact of LIA on longterm functional outcome, as well as to establish a gold standard for the administration of LIA.

\section{Author contributions}

All authors had full access to the data, contributed to the study, approved the final version for publication, and take responsibility for its accuracy and integrity.

Concept or design: All authors.

Acquisition of data: YY Fang, QJ Lee, EWY Chang.

Analysis or interpretation of data: YY Fang, QJ Lee.

Drafting of the article: YY Fang.

Critical revision for important intellectual content: YY Fang.

\section{Declaration}

The study was presented in the 38th Annual Congress of the Hong Kong Orthopaedic Association, 3-4 November 2018, Hong Kong.

\section{Conflicts of interest}

All authors have disclosed no conflicts of interest.

\section{Funding/support}

This research received no specific grant from any funding agency in the public, commercial, or not-for-profit sectors.

\section{Ethics approval}

This study was approved by the Kowloon West Cluster Research Ethics Committee (Ref KW/EX-18-118[128-02]).

\section{References}

1. Xu CP, Li X, Wang ZZ, Song JQ, Yu B. Efficacy and safety of single-dose local infiltration of analgesia in total knee arthroplasty: a meta-analysis of randomized controlled 
trials. Knee 2014;21:636-46.

2. Kerr DR, Kohan L. Local infiltration analgesia: a technique for the control of acute postoperative pain following knee and hip surgery: a case study of 325 patients. Acta Orthop 2008;79:174-83.

3. Keijsers R, van Delft R, van den Bekerom MP, de Vires DC, Brohet RM, Nolte PA. Local infiltration analgesia following total knee arthroplasty: effect on post-operative pain and opioid consumption-a meta-analysis. Knee Surg Sports Traumatol Arthrosc 2015;23:1956-63.

4. Affas F. Local infiltration analgesia in knee and hip arthroplasty efficacy and safety. Scand J Pain 2016;13:5966.

5. de Jonge T, Görgényi S, Szabó G, Torkos MB. Local infiltration analgesia in total joint replacement [in Hungarian]. Orv Hetil 2017;158:352-7.

6. Barastegui D, Robert I, Palau E, et al. Can local infiltration analgesia increase satisfaction in postoperative short-term pain control in total knee arthroplasty? J Orthop Surg (Hong Kong) 2017;25:2309499017690461.

7. Seangleulur A, Vanasbodeekul P, Prapaitrakool S, et al. The efficacy of local infiltration analgesia in the early postoperative period after total knee arthroplasty: a systematic review and meta-analysis. Eur J Anaesthesiol 2016;33:816-31

8. Vaishya R, Wani AM, Vijay V. Local infiltration analgesia reduces pain and hospital stay after primary TKA: randomized controlled double blind trial. Acta Orthop Belg 2015;81:720-9.

9. Fan L, Yu X, Zan P, Liu J, Ji T, Li G. Comparison of local infiltration analgesia with femoral nerve block for total knee arthroplasty: a prospective, randomized clinical trial. J Arthroplasty 2016;31:1361-5.

10. Albrecht E, Guyen O, Jacot-Guillarmod A, Kirkham KR. The analgesic efficacy of local infiltration analgesia vs femoral nerve block after total knee arthroplasty: a systematic review and meta-analysis. Br J Anaesth 2016;116:597-609.

11. Mulford JS, Watson A, Broe D, Solomon M, Loefler A, Harris I. Short-term outcomes of local infiltration anaesthetic in total knee arthroplasty: a randomized controlled double-blinded controlled trial. ANZ J Surg 2016;86:152-6.

12. Bonnette BA. Is local infiltration analgesia (LIA) a safe and effective method for post-operative pain management after a unilateral total knee arthroplasty (TKA)? [dissertation]. US: Philadelphia College of Osteopathic Medicine; 2013.

13. Brydone AS, Souvatzoglou R, Abbas M, Watson DG, McDonald DA, Gill AM. Ropivacaine plasma levels following high-dose local infiltration analgesia for total knee arthroplasty. Anaesthesia 2015;70:784-90.

14. Knudsen K, Beckman Suurküla M, Blomberg S, Sjövall J, Edvardsson N. Central nervous and cardiovascular effects of i.v. infusions of ropivacaine, bupivacaine and placebo in volunteers. Br J Anaesth 1997;78:507-14.

15. Casati A, Putzu M. Bupivacaine, levobupivacaine and ropivacaine: are they clinically different? Best Pract Res Clin Anaesthesiol 2005;19:247-68.

16. Rowe PJ, Myles CM, Walker C, Nutton R. Knee joint kinematics in gait and other functional activities measured using flexible electrogoniometry: how much knee motion is sufficient for normal daily life? Gait Posture 2000;12:14355 .
17. Moxley Scarborough D, Krebs DE, Harris BA. Quadriceps muscle strength and dynamic stability in elderly persons. Gait Posture 1999;10:10-20.

18. Medical Research Council. Aids to the examination of the peripheral nervous system. Memorandum No 45 (superseding War Memorandum No. 7). London: Her majesty's stationery office. 1976. Available from: https:// mrc.ukri.org/documents/pdf/aids-to-the-examination-ofthe-peripheral-nervous-system-mrc-memorandum-no45-superseding-war-memorandum-no-7/. Accessed Nov 2018.

19. Affas F, Nygårds EB, Stiller CO, Wretenberg P, Olofsson C. Pain control after total knee arthroplasty: a randomized trial comparing local infiltration anesthesia and continuous femoral block. Acta Orthop 2011;82:441-7.

20. Rosen AS, Colwell CW, Pulido PA, Chaffee, TL, Copp SN. A randomized controlled trial of intraarticular ropivacaine for pain management immediately following total knee arthroplasty. HSS J 2010;6:155-9.

21. Lamplot JD, Wagner ER, Manning DW. Multimodal pain management in total knee arthroplasty: a prospective randomized controlled trial. J Arthroplasty 2014;29:32934.

22. Kurosaka K, Tsukada S, Seino D, Morooka T, Nakayama $\mathrm{H}$, Yoshiya S. Local infiltration analgesia versus continuous femoral nerve block in pain relief after total knee arthroplasty: a randomized controlled trial. J Arthroplasty 2016;31:913-7.

23. Tsukada S, Wakui M, Hoshino A. Postoperative epidural analgesia compared with intraoperative periarticular injection for pain control following total knee arthroplasty under spinal anesthesia: a randomized controlled trial. J Bone Joint Surg Am 2014;96:1433-8.

24. Tsukada S, Wakui M, Hoshino A. Pain control after simultaneous bilateral total knee arthroplasty: a randomized controlled trial comparing periarticular injection and epidural analgesia. J Bone Joint Surg Am 2015;97:367-73.

25. Tammachote N, Kanitnate S, Manuwong S, Yakumpor T, Panichkul P. Is pain after TKA better with periarticular injection or intrathecal morphine? Clin Orthop Relat Res 2013;471:1992-9.

26. Fajardo M, Collins J, Landa J, Adler E, Meere P, Di Cesare PE. Effect of a perioperative intra-articular injection on pain control and early range of motion following bilateral TKA. Orthopedics 2011;34:354.

27. Niemeläinen M, Kalliovalkama J, Aho AJ, Moilanen T, Eskelinen A. Single periarticular local infiltration analgesia reduces opiate consumption until 48 hours after total knee arthroplasty. A randomized placebo-controlled trial involving 56 patients. Acta Orthop 2014;85:614-9.

28. Garcia JB, Barbosa Neto JO, Vasconcelos JW, Ferro LS, Silva RC. Analgesic efficacy of the intra-articular administration of high doses of morphine in patients undergoing total knee arthroplasty [in English, Portuguese]. Rev Bras Anestesiol 2010;60:1-12.

29. Zhang S, Wang F, Lu ZD, Li YP, Zhang L, Jin QH. Effect of single-injection versus continuous local infiltration analgesia after total knee arthroplasty: a randomized, double-blind, placebo-controlled study. J Int Med Res 2011;39:1369-80.

30. Fan JC. Intra-operative periarticular multimodal injection in total knee arthroplasty: a local hospital experience in 
Hong Kong. Hong Kong Med J 2018;24:145-51.

31. Fu P, Wu Y, Wu H, Li X, Qian Q, Zhu Y. Efficacy of intra-articular cocktail analgesic injection in total knee arthroplasty-a randomized controlled trial. Knee 2009;16:280-4.

32. Busch CA, Shore BJ, Bhandari R, et al. Efficacy of periarticular multimodal drug injection in total knee arthroplasty. A randomized trial. J Bone Joint Surg Am 2006;88:959-63.

33. Essving P, Axelsson K, Kjellberg J, Wallgren O, Gupta A, Lundin A. Reduced morphine consumption and pain intensity with local infiltration analgesia (LIA) following total knee arthroplasty. Acta Orthop 2010;81:354-60.

34. Aldridge SC, Comerota AJ, Katz ML, WolkJH, Goldman BI, White JV. Popliteal venous aneurysm: report of two cases and review of world literature. J Vasc Surg 1993;18:708-15

35. Sessa C, Nicolini P, Perrin M, Farah I, Magne JL, Guidicelli
H. Management of symptomatic and asymptomatic popliteal venous aneurysms: a retrospective analysis of 25 patients and review of the literature. J Vasc Surg 2000;32:902-12.

36. Sadowska A, Spodnik JH, Wójcik S. Variations in popliteal fossa venous anatomy: implications for diagnosis of deepvein thrombosis. Folia Morphol (Warsz) 2013;72:51-6.

37. Jimenez F, Utrilla A, Cuesta C, et al. Popliteal artery and venous aneurysm as a complication of arthroscopic meniscectomy. J Trauma 1988;28:1404-5.

38. Boutchichi A, Ciornohac J, Daubresse F. Pseudoaneurysm after total knee arthroplasty: a rare complication with different possible clinical presentations. Acta Orthop Belg 2013;79:16-9.

39. Agarwala SR, Mohrir GS, Dotivala SJ. Posttraumatic pseudoaneurysm of popliteal artery following total knee arthroplasty. Indian J Orthop 2013;47:101-3. 